\title{
DiferenÇAS MORFOLóGICAS ENTRE Amaranthus cruentus, CV. BRS Alegria, e AS Plantas DANINHAS A. hybridus, A. retroflexus, A. viridis e A. spinosus ${ }^{1}$
}

\author{
Morphological Differences Between Amaranthus cruentus, $c v$. BRS Alegria, and the Weed \\ Species A. hybridus, $A$. retroflexus, $A$. viridis and A. spinosus
}

\begin{abstract}
SPEHAR, C.R. ${ }^{2}$
RESUMO - O pseudocereal amaranto, com as espécies Amaranthus caudatus, A. cruentus e A. hypochondriacus, domesticado pelas populações indígenas antes que a América fosse descoberta, tem se adaptado aos sistemas produtivos dos cerrados. A planta apresenta panículas apicais, divididas em pequenos ramos com frutos do tipo pixídio, com uma semente cada. Estas germinam rapidamente em presença de umidade, após atingirem a maturação fisiológica. No início da fase vegetativa, o amaranto cultivado pode confundir-se com espécies de plantas daninhas do mesmo gênero (A. hybridus, A. retroflexus, A. viridis e A. spinosus), as quais estão associadas à expansão agrícola. As diferenças morfológicas tornam-se mais visíveis após o florescimento: ramificações com flores axilares e terminais, em contraste com o amaranto, no qual a inflorescência (panícula) é apical; as sementes claras das espécies cultivadas contrastam com as das invasoras, que são escuras. BRS Alegria (A. cruentus), cultivar pioneiro no Brasil, apresenta plantas com $180 \mathrm{~cm}$, das quais a panícula ocupa $48 \mathrm{~cm}$; maturação fisiológica aos 90 dias; resistência ao acamamento; e 0,68 g por 1.000 sementes, com produção de 2,3 t ha ${ }^{-1}$ (sementes) e 5,6 t ha' ${ }^{-1}$ (biomassa total). As sementes nas plantas daninhas são menores, germinam gradativamente e podem permanecer no solo por muitos anos, infestando as áreas. As diferenças morfológicas detectadas na experimentação demonstram que as espécies são distinguíveis; elas contribuem para orientar a produção de sementes e o cultivo comercial de amaranto, enfatizando as características de adaptação, em contraste com as das invasoras do mesmo gênero botânico.
\end{abstract}

Palavras-chave: amaranto, caruru, germinação, dormência, caracterização.

\begin{abstract}
The pseudocereal grain amaranth, with the species Amaranthus caudatus, A. ruentus e A. hypochondriacus, domesticated by indigenous populations before America was discovered, has shown adaptability to production systems in the Brazilian savannah. The plants present apical panicles, divided into small branches which hold fruits (pixid type), containing one seed each. The seeds germinate quickly in the presence of moisture, after physiological maturity. At the early phase of development, grain amaranth can be confounded with the weed species A. hybridus, A. retroflexus, A. viridis, A. spinosus, which are associated with agricultural expansion in the savannah. Their morphological differences become more visible after flowering: branching, with axilary and terminal flowers in weed types contrasting with cultivated amaranth, in which panicles are apical; the light coloured seed testa contrasts with the black seed testas of the weed species. BRS Alegria (A. cruentus), the pioneer cultivar in Brazil, presents $180 \mathrm{~cm}$ plant height, of which the panicle occupies $48 \mathrm{~cm}$; physiological maturity at 90 days; resistance to lodging; seed weight of $0.68 \mathrm{~g}$ per 1.000 , with yields of $2.3 \mathrm{th} \mathrm{a}^{-1}$ (seed) and $5.6 \mathrm{t} \mathrm{ha}^{-1}$ (total biomass). The seeds of weed types are smaller, germinate gradually and may remain in soil for many years, infesting cultivated areas. The morphological differences detected under experimentation show that the species are distinguishable; they contribute to guiding grain amaranth seed production and commercial cultivation, emphasizing adaptation characteristics, in contrast to $t$ weed seeds from the same botanical genus.
\end{abstract}

Key words: grain amaranth, germination, dormancy, characterization.

Recebido para publicação em 27.5.2003 e na forma revisada em 12.12.2003.

Eng.-Agr., Ph.D., Pesquisador, Líder de Projeto, EMBRAPA-Centro de Pesquisa Agropecuária dos Cerrados, Caixa Postal 08223, 73301-970 Planaltina-DF.

Planta Daninha, Viçosa-MG, v.21, n.3, p.481-485, 2003 


\section{INTRODUÇÃO}

Desde meados dos anos 1990, a Embrapa, apoiada pelo $\mathrm{CNPq}$, tem realizado trabalho pioneiro com três das principais espécies de amaranto, na adaptação do pseudocereal ao cultivo no Brasil (Teixeira, 2000). A espécie Amaranthus caudatus é originária dos Andes, enquanto A. cruentus e A. hypochondriacus, do México, foram domesticadas pelos povos americanos há milênios (Brenner et al., 2000; Tapia, 1997).

O amaranto cultivado apresenta óleo e proteína em quantidade e qualidade superior à dos cereais (Spehar et al., 2003). Esta, comparável à caseína do leite, o torna um cultivo potencial. Por ser mais equilibrada em aminoácidos essenciais, pode complementar a alimentação de humanos, aves e suínos com vantagem sobre os cereais e a soja, quando empregados isoladamente (Brenner \& Williams, 1995; Rivero, 1994). A demanda é crescente no mundo, principalmente como alimento de qualidade, com baixo colesterol; pode ser usada em dietas especiais, destinadas a pacientes celíacos - pessoas alérgicas ao glúten -, no enriquecimento de alimentos como pães e biscoitos e na culinária em geral (Teixeira et al., 2002).

Pela semelhança da planta, durante as fases iniciais do desenvolvimento, o amaranto pode confundir-se com espécies de plantas daninhas do mesmo gênero (A. hybridus, A. retroflexus, $A$. viridis e $A$. spinosus), conhecidas pelo nome genérico de caruru ou bredo (no Nordeste brasileiro). Estas dispersaram-se no Brasil, associadas à expansão agrícola (Coons, 1981).

As espécies cultivadas apresentam ciclo entre 90 e 100 dias, nas condições do Brasil Central. Após 20-30 dias da semeadura, o crescimento é rápido e podem atingir até $2,0 \mathrm{~m}$ em semeaduras de safrinha (fevereiro-março), com suprimento de $300 \mathrm{~mm}$ de água. O sistema radicular vigoroso e o ciclo curto possibilitam ao amaranto tolerar os estresses hídricos e produzir grãos e biomassa para a proteção do solo, nas mesmas condições que sorgo, milheto e girassol (Spehar, 1998; Spehar \& Cabezas, 2001).

O amaranto apresenta frutos do tipo pixídio, com apenas uma semente, que estão presos a uma panícula (inflorescência) apical, dividida em pequenos ramos (Tapia, 1997). As sementes de coloração clara, quando amadurecem, apresentam rápida germinação na presença de umidade.

BRS Alegria, A. cruentus, é o primeiro cultivar recomendado em nosso país (Spehar et al., 2003) e apresenta as seguintes características botânicas: hipocótilo com coloração rósea; folhas grandes, alongadas, verdes, com coloração rósea da nervura, na face abaxial; caule ereto, de coloração rósea; e inflorescência diferenciada, apical, compacta, rósea, a qual permanece mesmo após a planta atingir a maturação fisiológica. O fruto, pixídio típico, deiscente, prende-se aos ramos da panícula; a semente, uma por fruto, é arredondada e de coloração bege.

As características agronômicas de BRS Alegria são: planta com estatura média de $180 \mathrm{~cm}$, da qual a inflorescência ocupa $48 \mathrm{~cm}$; diferenciação floral aos 30 dias após a emergência e a antese aos 45 dias; período entre a emergência e a maturação fisiológica de 90 dias; e resistência ao acamamento. O peso

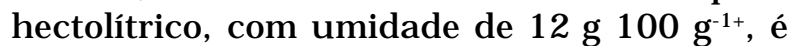
de $0,68 \mathrm{~g}$ por 1.000 sementes. Estas apresen-

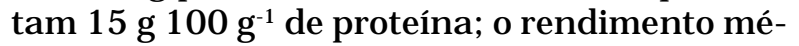
dio é de 2,3 t ha ${ }^{-1}$ (grãos) e 5,6 tha ${ }^{-1}$ (biomassa total). As plantas demoram a secar após a maturação; no cerrado, quando a semeadura se dá no período da safrinha, as plantas amadurecem em pleno período de seca, o que permite uma secagem adequada para a colheita dos grãos (Spehar et al., 2003).

As produções comerciais se iniciam no Brasil, como alternativa de sucessão (safrinha) no sistema plantio direto. Espera-se que o grão seja utilizado pelas indústrias de alimentos e rações (Spehar et al., 2003). A planta inteira, como forragem na alimentação animal, pode integrar o sistema lavoura-pecuária (Spehar \& Cabezas, 2001). Daí a importância de se distinguir o amaranto cultivado das espécies invasoras.

Este trabalho objetivou estabelecer parâmetros de diferenciação morfológica entre o amaranto domesticado, cultivar BRS Alegria, e as espécies invasoras mais comuns no cerrado, para apoio à produção de sementes e ao cultivo comercial. 


\section{MATERIAL E MÉTODOS}

O experimento, com delineamento inteiramente casualizado e quatro repetições, foi conduzido em vasos, em casa de vegetação. O substrato foi composto por uma parte de matéria orgânica (composto) e duas de solo. Essa mistura foi adubada para atender a demanda das plantas, até que atingissem a maturação fisiológica. Os tratamentos foram constituídos de amaranto, cultivar BRS Alegria (A. cruentus), A. viridis, A. retroflexus, A. hybridus ssp. patulus, A. hybridus ssp. paniculatus e A. spinosus. As sementes das espécies de plantas daninhas foram coletadas em áreas de lavoura na região do cerrado. Quinze sementes de amaranto e 30 das espécies de plantas daninhas foram semeadas em vasos com capacidade de 3 litros; o desbaste se deu quando as plantas apresentavam a primeira folha verdadeira totalmente expandida, deixando-se quatro plantas/vaso. Nas espécies daninhas, com germinação em período mais longo, fez-se desbaste adicional, para manter o mesmo número. A umidade foi mantida mediante o uso de bandejas sob os vasos, as quais receberam a mesma quantidade de água, suficiente para suprir a demanda das plantas. Os turnos de rega se repetiram a cada dois dias.

Durante a condução, avaliaram-se as seguintes características: comprimento e largura (cm) da sétima folha, após as cotiledonares, totalmente expandida; cor da nervura principal e do pecíolo, na maturação fisiológica; ramificação do caule ( 1 - menos ramificado; 4 - mais ramificado); tipo (determinado ou indeterminado), comprimento e largura da panícula; ocorrência da antese (dias após a emergência); peso, cor, quantidade e germinação da semente. Os dados relativos a tamanho de folhas e pecíolo, altura de planta, número de sementes por planta e o seu peso para cada tratamento foram analisados e as médias comparadas pelo teste de Tukey a $5 \%$ de probabilidade.

\section{RESULTADOS E DISCUSSÃO}

Em amaranto cultivado, BRS Alegria (A. cruentus), e nas espécies de plantas daninhas, na fase vegetativa, a planta pode variar nos aspectos de coloração e tamanho das folhas (Tabela 1). Entretanto, após a floração, as diferenças se acentuam: ramificação nas plantas daninhas, com inflorescências axilares e apicais em todos os ramos, em contraste com amaranto cultivado, no qual as panículas são apicais, com diversas colorações, entre amarelo e vermelho-escuro. O crescimento do amaranto cultivado é mais vigoroso e a biomassa que produz constitui alternativa para proteção do solo em plantio direto no cerrado (Spehar, 1998; Spehar \& Cabezas, 2001).

Ainda que a coloração avermelhada das nervuras na folha, em Amaranthus hybridus ssp. paniculatus, possa confundir-se com BRS Alegria, as diferenças se verificam na altura de plantas e coloração da semente - escura e dormente na primeira, típica de planta daninha. As sementes, desta e das demais espécies, são menores; com grande quantidade por planta, germinam gradativamente e permanecem no solo por longo período, podendo infestar as áreas agrícolas (Coons, 1981; Spehar et al., 2003).

Os dados experimentais relativos a altura de plantas, tamanho de folha, tipo de caule e de panícula, ocorrência da antese, tamanho, cor, quantidade e germinação de sementes (Tabela 1) mostram que o cultivar BRS Alegria apresenta plantas consideravelmente mais altas, com folhas e pecíolos maiores do que as espécies de planta daninha; nestas, as flores ocorrem distribuídas pelas ramificações do caule. As espécies A. viridis $e$ A. retroflexus, com menor ramificação dentre as plantas daninhas, contrastam com o amaranto, no qual se concentram na inflorescência principal.

Quanto à densidade e ao tamanho, a inflorescência em amaranto cultivado é compacta ou laxa, enquanto a planta daninha apresentase ramificada; as sementes nas espécies de plantas daninhas apresentam tamanho variando entre 0,23 , em $A$. spinosus, e $0,39 \mathrm{~g}$ por $1.000 \mathrm{em} A$. hybridus. ssp. paniculatus; a taxa de germinação nessas espécies, após a maturação fisiológica, é reduzida quando comparada à do amaranto BRS Alegria; o ciclo total (número de dias da emergência à maturação) é maior no amaranto cultivado. Parte das características morfológicas de diferenciação da planta e da semente de amaranto cultivado e planta daninha é apresentada na Figura 1.

Planta Daninha, Viçosa-MG, v.21, n.3, p.481-485, 2003 
Tabela 1 - Diferenças fenotípicas entre o amaranto cultivado (A. cruentus, cv. BRS Alegria) e espécies de planta daninha, relativas a folha, planta, inflorescência e semente. Embrapa Cerrados, entressafra, 2002

\begin{tabular}{|c|c|c|c|c|c|c|c|}
\hline \multirow[b]{2}{*}{ Caráter } & \multicolumn{6}{|c|}{ Espécie } & \multirow{2}{*}{$\begin{array}{l}\mathrm{CV} \\
(\%)\end{array}$} \\
\hline & $\begin{array}{l}\text { A. cruentus } \\
\text { BRS Alegria }\end{array}$ & A. viridis & A. retroflexus & $\begin{array}{l}\text { A. hybridus } \\
\text { ssp. patulus }\end{array}$ & $\begin{array}{l}\text { A. hybridus. ssp. } \\
\text { paniculatus }\end{array}$ & A. spinosus & \\
\hline \multicolumn{7}{|c|}{ Folha } & \\
\hline Comprimento $(\mathrm{cm})$ & $20,0 \mathrm{a}^{-1 /}$ & $15,6 \mathrm{~b}$ & $9,5 \mathrm{~d}$ & $12,5 \mathrm{c}$ & $11,0 \mathrm{c}$ & $8,9 \mathrm{~d}$ & 7,4 \\
\hline Largura $(\mathrm{cm})$ & $10,5 \mathrm{a}$ & $7,9 \mathrm{~b}$ & $6,5 \mathrm{bc}$ & $7,5 \mathrm{~b}$ & $7,5 \mathrm{~b}$ & $5,8 \mathrm{c}$ & 8,9 \\
\hline Pecíolo $(\mathrm{cm})$ & $15,0 \mathrm{a}$ & $10,7 \mathrm{~b}$ & $5,7 \mathrm{~cd}$ & $8,7 \mathrm{bc}$ & $8,5 \mathrm{bc}$ & $7,3 \mathrm{c}$ & 6,7 \\
\hline Cor do pecíolo* & rosa & verde & rosa & rosa & rosa & rosa & \\
\hline Cor da nervura* & rosa & verde & rosa & rosa & rosa & rosa & \\
\hline \multicolumn{7}{|c|}{$\begin{array}{l}\text { *na maturação fisiológica } \\
\text { Planta/Inflorescência }\end{array}$} & \\
\hline Ramificação** & 1 & 2 & 2 & 4 & 3 & 4 & \\
\hline Altura $(\mathrm{cm})$ & $172 \mathrm{a}$ & $133 b$ & $86 \mathrm{~d}$ & $115 c$ & $105 \mathrm{~cd}$ & $81 \mathrm{~d}$ & 11,3 \\
\hline Antese (dias) & 45 & 35 & 35 & 33 & 33 & 30 & \\
\hline Tipo*** & D & D & I & I & I & I & \\
\hline Comprimento $(\mathrm{cm})$ & 35,0 & 20,0 & 40,0 & 32,0 & 40,0 & 26,0 & \\
\hline Largura $(\mathrm{cm})$ & 13,0 & 3,0 & 8,0 & 5,0 & 7,0 & 7,5 & \\
\hline \multicolumn{7}{|c|}{$\begin{array}{c}* * 1=\text { pouco ramificado } ; 4=\text { muito ramificado } * * * \mathrm{D}=\text { determinado } ; \mathrm{I}=\text { Indeterminado } \\
\text { Semente }\end{array}$} & \\
\hline Peso (g por 1.000$)$ & $0,70 \mathrm{a}$ & $0,35 \mathrm{~b}$ & $0,35 \mathrm{~b}$ & $0,34 \mathrm{~b}$ & $0,39 \mathrm{~b}$ & $0,23 \mathrm{c}$ & 4,8 \\
\hline Cor & bege & preta & Preta & preta & preta & preta & \\
\hline $\begin{array}{l}\text { Sementes por } \\
\text { planta }\end{array}$ & $1.243 \mathrm{a}$ & $972 \mathrm{~b}$ & $834 \mathrm{~b}$ & $643 c$ & $785 \mathrm{bc}$ & $436 \mathrm{~d}$ & 7,9 \\
\hline Germinação**** & 99 & 15 & 16 & 13 & 18 & 23 & \\
\hline
\end{tabular}

1/ Números seguidos pela mesma letra, em uma mesma linha, não diferem entre si (Tukey, $\mathrm{p} \leq 0,05$ ).

**** Percentagem de germinação, obtida trinta dias após a maturação fisiológica.

As espécies de amaranto planta daninha, com inflorescência ramificada, menor tamanho da apical e sementes menores e escuras, se tornam distintas das espécies cultivadas. A reduzida germinação das sementes ocorre por baixa permeabilidade da casca ou testa. No amaranto BRS Alegria, as características de maturação uniforme, as panículas com dominância apical, concentradas no topo da planta, favoráveis à colheita mecanizada e as sementes claras, não dormentes, eliminam a possibilidade de ela se tornar invasora (Spehar et al., 2003).

Em áreas infestadas com espécies de planta daninha, quando a germinação coincide com a do amaranto cultivado, a produção de sementes e o cultivo comercial ficam comprometidos. As espécies podem produzir híbridos férteis entre si, por cruzamentos naturais. Nesse caso, o caráter indesejável de cor da semente pode ser transferido ao amaranto cultivado; por outro lado, pode-se excluí-lo via seleção, pois é de herança simples, condicionado a um par de genes dominantes (Brenner et al., 2000).

No Brasil, até o momento, não têm sido registrados híbridos espontâneos entre as espécies cultivadas e daninhas. Entretanto, em cultivos comerciais, será necessário um manejo adequado de amaranto planta daninha anterior à semeadura, no caso de grandes infestações, sob risco de contaminar o material colhido.

Na produção de sementes, o rigor na exclusão do amaranto planta daninha deverá ser ainda maior. A experimentação tem mostrado que, em sistemas integrados lavoura-pastagem, a semeadura do amaranto BRS Alegria, após a dessecação da gramínea, resulta em cultivos com baixa incidência das espécies daninhas do mesmo gênero, tornando a produção viável (Spehar et al., 2003). 


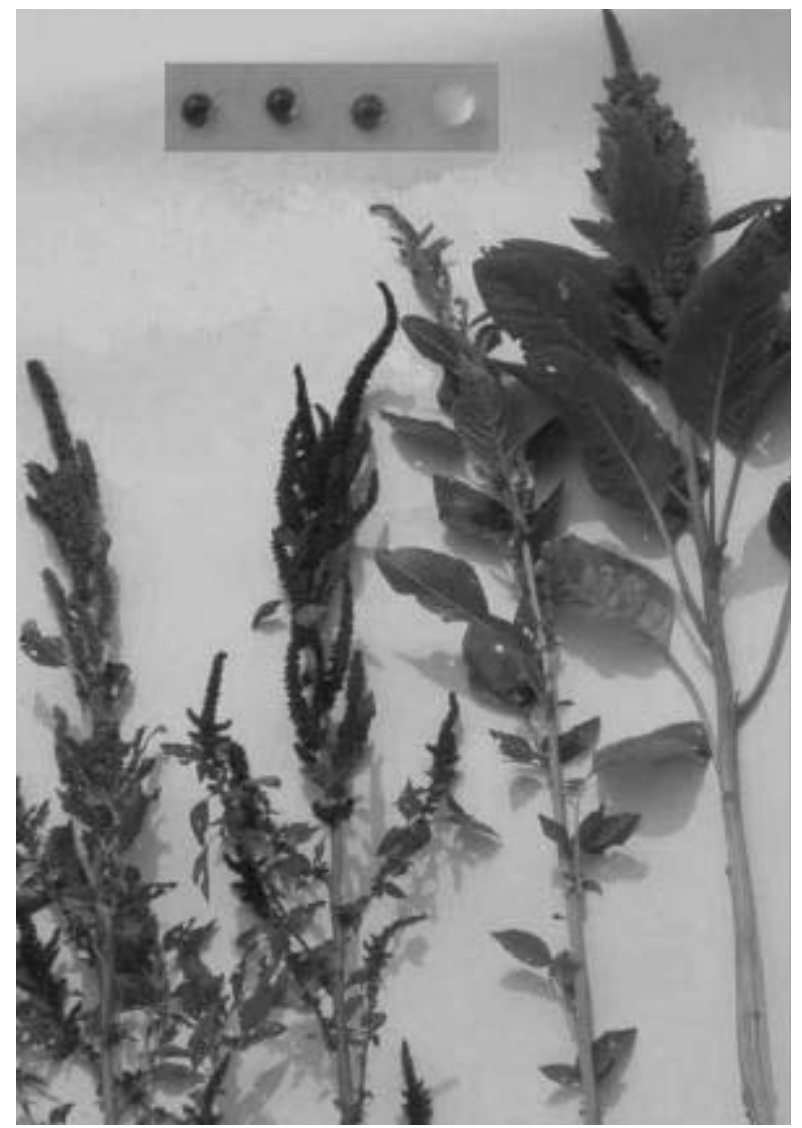

Figura 1 - Plantas e sementes de Amaranthus cruentus, cultivar BRS Alegria, A. viridis, A. retroflexus e A. hybridus ssp. paniculatus.

Com base nas diferenças morfológicas, o amaranto cultivado BRS Alegria (A. cruentus), além de se distinguir das espécies do mesmo gênero, invasoras de ampla dispersão nas áreas agrícolas, apresenta características agronômicas desejáveis ao cultivo comercial.

\section{LITERATURA CITADA}

BRENNER, D. M. et al. Genetic resources and breeding of Amaranthus. In: JANICK, J. (Ed.). Plant Breed. Rev., v. 19. p. $227-285,2000$.

BRENNER, D. M.; WILLIAMS, J. T. Grain amaranth (Amaranthus species). In: WILLIAMS, J. T. (Ed.). Underutilized crops: cereals and pseudocereals. London, Chapman \& Hall, 1995. p. 128-186.

COONS, M. P. O gênero Amaranthus em Minas Gerais. Experientiae, v. 27, n. 6, p. 115-158, 1981.

RIVERO, J. L. L. Genética y Mejoramiento de cultivos altoandinos. Puno, Peru : PIWA, 1994. 459 p.

SPEHAR, C. R. Production systems in the savannas of Brazil: Key factors to sustainability. In: LAL, R. (Ed.). Soil quality and agricultural sustainability. Chelsea: Ann Arbor Press, 1998. p. 301-318.

SPEHAR, C. R.; CABEZAS, W. A. R. L. Introdução e seleção de espécies para a diversificação do sistema produtivo nos cerrados. In: CABEZAS, W. A. R. L.; FREITAS, P. L. (Eds.). Plantio direto na integração lavoura pecuária. Uberlândia: Universidade Federal de Uberlândia. 2001. p. 179-188.

SPEHAR, C. R. et al. Amaranto BRS Alegria - alternativa para diversificar os sistemas de produção. Pesquisa Agropecuária Brasileira, v. 39, n. 1, p. 85-91, 2003.

TAPIA, M. Cultivos andinos subexplotados y su aporte a la alimentación. Santiago, Chile : Oficina Regional de la FAO para la América Latina y Caribe, 1997. 217 p.

TEIXEIRA, D. L. Introdução e caracterizaçãa agronômica de amaranto (Amaranthus spp. L.) na entressafra no Cerrado. 2000. 26 f. (Tese B.Sc.) Universidade de Brasília, Brasília, 2000.

TEIXEIRA, D. L.; SPEHAR, C. R.; SOUZA, L. A. C. Caracterização agronômica de amaranto na entressafra do cerrado. Pesquisa Agropecuária Brasileira, v. 38, n. 1, p. 85-91, 2002. 